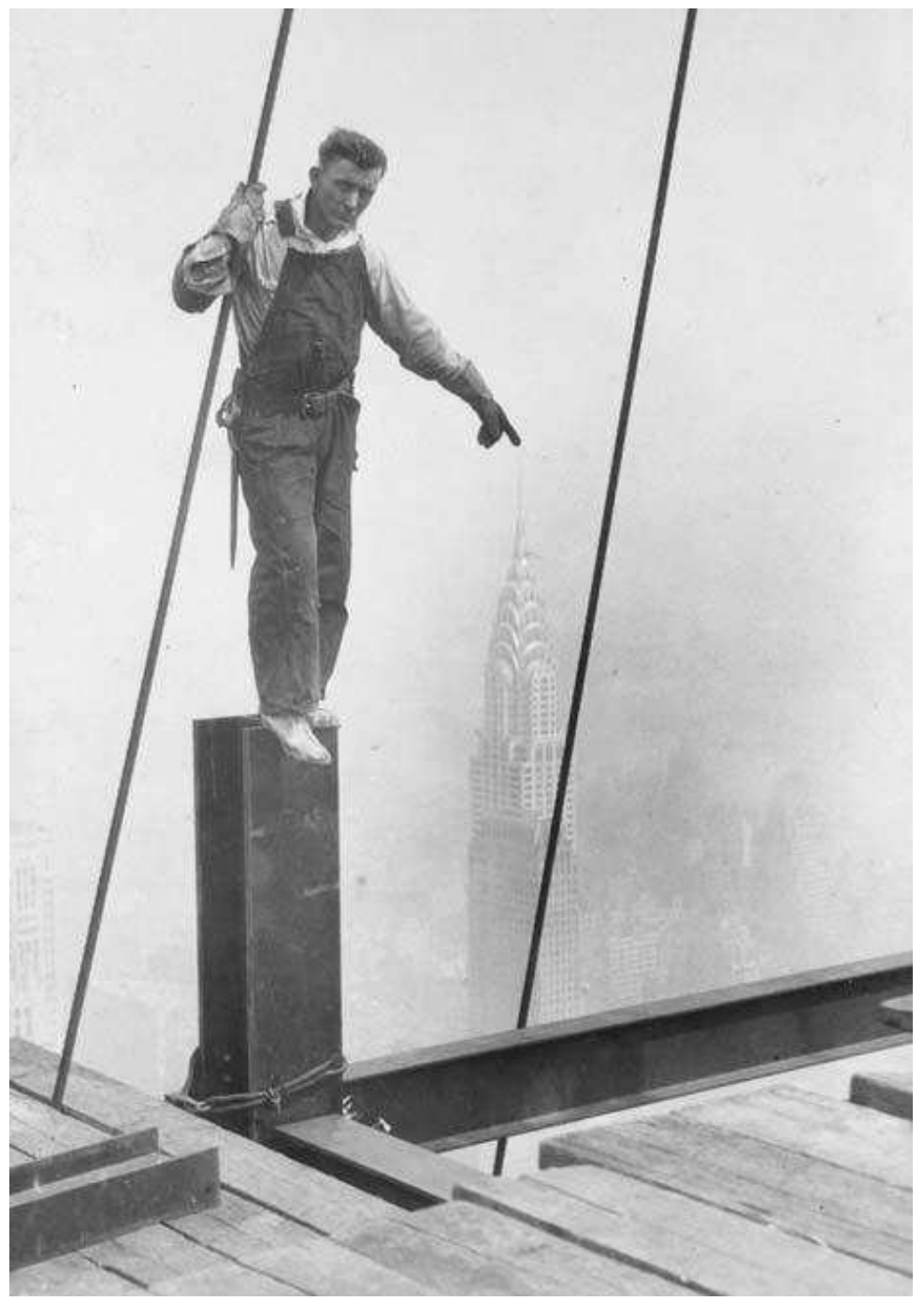

Construção do Empire State Building, Lewis Hine (1874-1940), Nova lorque, EUA, 1930, acervo George Eastman House. 


\title{
O trabalho em serviços:
contribuições para o
debate do Serviço Social
}

The work in services: contributions to the debate in Social Work

\author{
Fernanda Schütz* \\ Regina Célia Tamaso Mioto**
}

\begin{abstract}
Resumo: $O$ presente artigo trata da temática dos serviços através de uma breve revisão de literatura, visando ampliar o debate sobre a inserção dos assistentes sociais no campo dos serviços sociais, à luz das transformações no mundo do trabalho. Para tanto, faz-se uma pequena revisão em torno do trabalho produtivo e improdutivo, em Marx, e uma pequena exposição sobre a produção da sociologia do trabalho. Na esteira deste debate são traçadas algumas considerações acerca dos serviços, que indicam a impossibilidade da captura total deste trabalho, enquanto trabalho vivo, embora sejam cada vez mais presentes as formas de controle sobre ele. Partindo destas considerações, realiza-se uma reflexão acerca de alguns limites e possibilidades do trabalho profissional do assistente social. Posteriormente, são feitas as considerações finais.

Palavras-chave: serviços; serviço social; trabalho profissional.
\end{abstract}

\begin{abstract}
This article addresses the issue of services through a brief literature review, seeking to broaden the debate about the insertion of social workers in the field of social services, in the light of transformations in the world of work. To do so, it examines the concepts of productive and unproductive work in Marx, and present a brief exposition on the sociology of work Within this debate, some considerations are outlined about services, which indicate the impossibility of completely capturing this labor as living labor, although forms of control over this labor are increasingly present. Based on these considerations, we make a reflection about some limits and possibilities for the professional exercise of social work and final considerations are presented.
\end{abstract}

Keywords: services; social work; professional work.

\footnotetext{
* Assistente social do Hospital Universitário e mestranda do Programa de Pós-Graduação da Universidade Federal de Santa Catarina (UFSC). Endereço: Campus da UFSC - HU - Rua Prof. Maria Flora Pausewang, s/n. - Trindade - Florianópolis/SC, 88036-800 E-mail: <fernanda. schutz18@gmail.com>.

** Assistente social, pós-doutorado em Antropologia - Universidade de Perugia/Itália e professora associada do Departamento de Serviço Social e Pós-Graduação da Universidade Federal de Santa Catarina (UFSC). Endereço: Campus da UFSC, CSE, Departamento de Serviço Social, sala 10. CEP: 88040-900. Florianópolis/SC. E-mail: <mioto@cse.ufsc.br>.
} 


\section{Introdução}

No capitalismo monopolista assiste-se a um crescimento do setor de serviços. Com o desenvolvimento das forças produtivas, os serviços são incorporados pelo Estado para atender necessidades coletivas. Estas vinculadas principalmente a reprodução da força de trabalho. Ao mesmo tempo, os serviços se tornam parte dos interesses do sistema capitalista como atividades lucrativas. Segundo Costa (1998, p.109): "[...] quando as necessidades de reprodução transitam do campo das necessidades individuais para o campo das necessidades coletivas é que surgem os serviços de consumo coletivo, superando a esfera das práticas privadas."

Para Braverman (1974, p.239), a urbanização e as mudanças na configuração das famílias no contexto do desenvolvimento do capitalismo monopolista são os elementos que demandam o crescente aumento dos serviços. Na opinião do autor, sentimentos de pertença à vizinhança e à comunidade são abalados, ao mesmo tempo em que as famílias perdem em parte a aptidão para o cuidado, pois muitos de seus membros passam a se inserir no mercado de trabalho. "[...] O cuidado dos seres humanos uns para com os outros torna-se cada vez mais institucionalizado". (BRAVERMAN, 1974, p.238).

A urbanização e o aumento do ritmo da vida social e econômica cria a necessidade de o Estado incorporar serviços tais como educação, saúde pública, serviço postal. Assim, principalmente a partir do capitalismo monopolista, são desenvolvidas formas de intervenção social. Para a realização destas formas específicas de intervenção social torna-se necessária a participação de alguns profissionais na materialização das políticas sociais. Entre estes profissionais está o assistente social.

Isto pode ser posto na medida em que podemos observar a participação dos profissionais de Serviço Social na criação de condições necessárias ao processo de reproduçã̃o social, através de ações que tanto incidem sobre as condições de vida dos trabalhadores (saúde, alimentação, educação, habitação, lazer, dentre outros), quanto produzem efeitos ideológicos que reforçam (ou não) a aceitação das condições de compra e venda da força de trabalho. (TRINDADE, 2004, p. 21).

Nessa perspectiva, a temática dos serviços e, particularmente, dos serviços sociais ganha relevância para o Serviço Social e este artigo tem o intuito de ampliar o debate em torno do trabalho do assistente social no âmbito dos serviços sociais. Considera-se que seu processo de trabalho é condicionado pelas transformações do mundo do trabalho, com a inserção de novos padrões organizacionais, bem como pelas inflexões no campo da intervenção estatal no campo da provisão do bem-estar social, inflexões estas com estreita relação com estágios de desenvolvimento econômico. Concomitantemente, observa-se também que a dinâmica dos serviços sociais é afetada por tais processos. 
Para a sustentação desse debate recorre-se a uma breve revisão de literatura. Esta é apresentada em dois momentos. O primeiro se concentra na ideia de trabalho produtivo e improdutivo, em Marx, considerando-se que ela dá subsídios para pensar os serviços numa perspectiva crítica. No segundo momento são expostas algumas contribuições da sociologia do trabalho, partindo-se de Clauss Offe (1989) e de análises de Amorim (2009; 2010) acerca dos autores que forjam contribuições do trabalho imaterial. Dentro destas perspectivas os serviços podem ser compreendidos em linhas que se afastam do pensamento marxiano. Neste debate, são traçadas reflexões acerca dos serviços que indicam a impossibilidade da captura total deste trabalho, enquanto trabalho vivo, devido a forte dependência dos serviços dos atributos humanos. A partir desse contexto centraliza-se o debate no campo do Serviço Social, com destaque às contribuições de lamamoto (2010), enfatizando alguns limites e possibilidades do exercício profissional do assistente social. Posteriormente, são feitas as considerações finais.

\section{O debate sobre o trabalho produtivo e improdutivo}

A perspectiva de Marx - na qual se busca aqui subsídios para pensar a atividade de serviços - repousa na teoria do valor trabalho. A preocupação de Marx busca compreender como são forjadas as relações de produção e como são reproduzidas no tecido social. Neste aspecto, postula a historicidade e especificidade do modo de produção capitalista, o qual tem aparência fetichizada, obscurecendo sua compreensão. Este processo é escamoteado pela constituição do valor de troca. Sua manifestação obscurece o trabalho concreto despendido na produção. Para Marx (2011), o trabalho é substância criadora de valor e, conseqüentemente, a quantidade de valor é determinada pelo tempo de trabalho gasto na produção, ou o tempo socialmente necessário a esta produção. "O verdadeiro valor de uma mercadoria, porém, não é o valor individual, e sim o social; não se mede pelo tempo de trabalho que custa realmente em cada caso, mas pelo tempo socialmente exigido para sua produção." (MARX, 2011, p.368). Nesta relação, a produção de valor para o capital decorre ou do aumento do tempo da jornada de trabalho, mais-valia absoluta, ou de se diminuir o tempo necessário, mais-valia relativa, o que é particularmente facilitado pelo aumento da produtividade.

Nesta perspectiva, se desenvolve sua concepção marxiana de trabalho produtivo e improdutivo. É trabalho produtivo o que serve para a autovalorização do capital.

Como o fim imediato e (o) produto por excelência da produção capitalista é mais-valia, temos que somente é produtivo aquele trabalho que e só é trabalhador produtivo aquele possuidor da capacidade de trabalho que diretamente produza mais-valia; por isso, só aquele tra- 
balho que seja consumido diretamente no processo de produção com vista à valorização do capital. (MARX, 1969, p. 108).

Para Marx, aspecto central para compreender a apreensão de trabalho produtivo e improdutivo não se vincula à natureza dos processos de trabalho nem à sua utilidade "[...] (BRAVERMAN, 1974, p. 348). Marx avança neste sentido em relação aos fisiocratas, aos mercantilistas e aos economistas clássicos Estes relacionavam o trabalho produtivo à forma de trabalho em maior ênfase em suas épocas. Assim, para os fisiocratas o trabalho produtivo era o trabalho agrícola. Os mercantilistas atribuíam maior importância ao trabalho que trazia metais preciosos. E economistas, ao trabalho fabril (BRAVERMAN, 1974)

Ao mesmo tempo, para Marx, a não existência de uma base material não impede que o serviço possua valor de uso. "Um serviço nada mais é que um efeito útil de um valor de uso, seja da mercadoria seja do trabalho." (MARX, 1867, v.1, p.159 apud MEIRELLES, 2006, p.122). Todos os serviços são produtivos (com o resultado tangível ou intangível) se realizados em bases de produção capitalistas, produzindo mais-valia. Desse modo, para Marx (1969, p. 118), "Serviço não é, em geral, senão uma expressão para o valor de uso particular do trabalho, na medida em que este não é útil como coisa, mas como atividade".

Ele critica a idéia de que só é produtivo o trabalho que resulta num produto, visto que do ponto de vista do processo de produção, apenas é produtivo o trabalho que valoriza o capital. Portanto, estas análises deixam patente que o trabalho é considerado produtivo, não pelo seu conteúdo ou por reproduzir um bem material, mas por produzir mais-valia que é apropriada pelo capital.

Marx denota que "as determinações ulteriores do trabalho produtivo derivam diretamente dos traços que caracterizam o processo capitalista de produção" (MARX, 1969, p.111). Uma primeira premissa é que a força de trabalho é transformada em uma mercadoria, ou seja, o detentor da força de trabalho encara o capitalista como vendedor de trabalho vivo. Tratase de um trabalho assalariado. Outra premissa, é que capacidade de trabalho e o trabalho são incorporados como fatores vivos de produção do capital. Neste âmbito, Marx afirma que trabalhador produtivo é sempre um assalariado, mas nem todo assalariado é um trabalhador produtivo. Para o autor,

Quando se compra o trabalho para consumir o valor de uso, como serviço, não para colocar como fator vivo no lugar do valor do capital variável e o incorporar no processo capitalista de produção, o trabalho não é produtivo e o trabalhador assalariado não é trabalhador produtivo. (MARX, 1969, p.111).

No processo de produção, contrariamente, o capital quer produzir mais capital. Não é o valor de uso do trabalho para o consumo imediato 
que o capital quer produzir, mas sim mais-valia. E o capital só alcança esse produto específico do processo de produção capitalista, na troca pelo trabalho, que se chama por isso de trabalho produtivo. (MARX, 1987).

Deve-se frisar que o trabalho no âmbito dos serviços tinha uma importância menor dentro da produção capitalista, no contexto em que viveu Marx. Isso porque os serviços tinham uma presença bastante limitada se comparada com o presente na sociedade contemporânea. Tendo em vista o limite de tempo em que viveu Marx, pode-se dizer que ele teceu reflexões com importantes indicativos acerca dos serviços.

Para Rubin (1987), a diferenciação entre tipos de trabalho (na qual Marx fornece concepções acerca dos serviços) tem maior relevância para questão do trabalho produtivo, na qual há diferença entre trabalhos que se encarnam em valores de uso materiais e serviços que não adotam uma conformação objetiva, que não tem uma existência separada de seus executores, no qual a produção não pode se separar do ato de produzir.

Nesta direção, considera-se aqui, para pensar a questão dos serviços, a definição de Marx de serviço como atividade. Ela é de grande contribuição, pois traz à tona o caráter exclusivamente humano deste trabalho e que, portanto, não está submetida à captura total do trabalho vivo. Ou seja: o trabalho em serviços tem as particularidades que limitam sua captura integral. Corroborando esta dimensão, Marx acrescenta que no âmbito da produção não material há duas possibilidades:

1) $O$ resultado são mercadorias que existem isoladamente em relação ao produtor, ou seja, que podem circular como mercadorias no intervalo entre a produção e o consumo; por exemplo: livros, quadros, todos os produtos artísticos que se diferenciam da atividade artística do artista executante. A produção capitalista só se aplica aqui em forma muito limitada. [...]

2) O produto não é separável do ato de produção. Aqui também o modo capitalista de produção só tem lugar de maneira limitada e, pela própria natureza da coisa, não se dá senão em algumas esferas. (Necessito do médico, não de seu moleque de recados.) Nas instituições de ensino, por exemplo, os docentes podem ser meros assalariados para o empresário da fábrica de conhecimentos. Não se deve considerar o mesmo para o conjunto da produção capitalista. (MARX, 1969, p. 119-120 - grifos no original).

É com base nesses limites, fruto do caráter da atividade de serviços, que se traça a reflexão deste artigo. Neste intuito, busca-se articular esta reflexão ao exercício profissional, à medida que o assistente social trabalha na prestação de serviços à população. Ressalta-se a pertinência da análise de Marx acerca do trabalho produtivo e improdutivo, uma vez que relaciona a questão à forma social do trabalho, desvendando o modo de produção capitalista. Todavia, deve-se situar, ainda que de modo incipiente, algumas 
concepções, que envolvem o campo dos serviços, cujas postulações negam (ao mesmonos em parte) as postulações do pensamento marxiano.

\section{O debate sobre os serviços no contexto da reestruturação produtiva}

Refletir acerca da questão dos serviços supõe fazer algumas menções à última reestruturação produtiva, sobretudo por que ela afeta diretamente sua dinâmica. Os processos de reestruturação produtiva, iniciados nos anos 1970, tiveram grandes repercussões no mundo do trabalho. Esse processo foi objeto de diversas interpretações. Entre estas estão aquelas que afirmam a perda de centralidade do trabalho. O desenvolvimento da ciência e da tecnologia e a incorporação da automação nos sistemas produtivos foram elementos que aumentaram a produtividade do capital. Afiançou-se a tal progresso a liberação do tempo de trabalho dos indivíduos. Entretanto,

[...] o tempo liberado não permitiria qualificar qualquer possibilidade material de desenvolvimento do indivíduo social, pois esse tempo seria negativamente liberado pela forma do desemprego, da precarização, do subemprego, do banco de horas, etc. veiculando, assim, a impossibilidade efetiva de usufruto desse tempo liberado. (AMORIM, 2010, p. 167).

Valencia (2009), inclusive, denota que os novos paradigmas trazidos pela reestruturação produtiva, com o aumento da produtividade, (que evita o desperdício de tempo de trabalho), tendo como expoente o modelo de produção toyotista, intensificaram as formas de exploração do trabalho, como também aumentaram de diversas maneiras o prolongamento da jornada de trabalho. Isto significa o efetivo aumento de extração de mais-valia relativa e mais-valia absoluta. $\mathrm{O}$ asseveramento deste processo ocorre mediado pela implementação de formas mais eficientes de gestão e controle dos trabalhadores.

A produção contemporânea exige como requisitos do trabalhador a polivalência e a qualificação profissional. São impostos "novos processos de trabalho, de gestão do capital, de redefinição dos parâmetros de qualificação do trabalhador, de reordenamento das políticas públicas como também de redefinição das leis trabalhistas e das prioridades sociais ditadas pelo Estado" (AMORIM, 2009, p. 15). Concomitantemente, o aumento do desemprego, gerado no bojo da reestruturação produtiva, pressiona o trabalhador a assimilar as exigências de qualificação e a assumir novas funções. Intensifica-se o ritmo de trabalho. A própria subjetividade do trabalhador torna-se alvo do capital, uma vez que essa deve ser direcionada para "tomar decisões", visando aquilo que "é melhor para a empresa", enfim, a se en- 
volver com a política de "participação da empresa". (ANTUNES, 2001; VALENCIA, 2009).

Para Antunes (2001, p. 134), neste contexto, vem ocorrendo uma

maior interpenetração, entre atividades produtivas e as improdutivas, entre as atividades fabris e as de serviços, entre as atividades laborativas e as atividades de concepção, entre produção e conhecimento científico, que se expandem fortemente no mundo do capital e de seu sistema produtivo.

Os argumentos arrolados corroboram a centralidade do trabalho no processo societário contemporâneo. Entretanto, com a diminuição de postos de trabalho no setor industrial e aumento relativo no setor de serviços, têm sido veiculadas teorias que afirmam a perda de centralidade do trabalho, com base, entre outras, no crescimento dos serviços e/ou incorporação de alguns de seus atributos nos processos produtivos.

Destacam-se, nesse âmbito, as postulações de Offe (1989). O autor formula uma série de questionamentos acerca da centralidade do trabalho. Em sua opinião, o trabalho não seria a categoria adequada para explicar o funcionamento da sociedade. Entre os argumentos colocados ressalta-se aqui a questão da expansão do trabalho assalariado, que segundo Offe é acompanhada de sua diferenciação interna. Para o autor, a homogeneidade do trabalho é fundamentada em cinco aspectos: 1) dependência da força de trabalho em relação ao salário; 2) subordinação ao controle de autoridades; 3) risco de interrupção do trabalho por motivos diversos (exemplo, doença); 4) unificação da força de trabalho através das associações de classe (como sindicatos) e 5) o orgulho coletivo, pertencente à ideia de que trabalho produz riqueza e cultura. Para o autor, estes aspectos unificadores do trabalho não poderiam mais ser sustentados pela diversificação do mundo do trabalho. Dentre os argumentos, que rompem com a homogeneidade do trabalho, Offe (1989) ressalta aquele que diz respeito à diferença entre as formas de trabalho produtoras de bens e aquelas geradoras de serviços.

Segundo o autor, os critérios de racionalidade técnica e organizacional utilizados no setor primário e secundário, não podem ser transportados com a mesma nitidez para o setor de serviços. Consequentemente, o crescente aumento deste setor

[...] indica problemas de escassez e de eficiência, determinantes da racionalidade da produção industrial de bens, se confrontam com problemas de ordenamento e de normatização que não podem ser adequadamente processados com os meios de superação técnica e econômica da escassez, estando pelo contrário sujeitos a uma racionalidade própria do trabalho em serviços. Uma característica essencial daquele trabalho reflexivo em serviços me parece consistir em que ele mesmo elabora e mantém o próprio trabalho, e produz a produção mental e organizatoriamente. (OFFE, 1989, p.22-23). 
Para o autor os serviços carregam características de difícil previsibilidade e controle; não possuem critérios através dos quais possa se estabelecer tipo, volume e o momento de sua oferta. São ausentes referências que captem quantitativamente a utilidade gerada pela prestação do serviço. Além disto, não existem referências sobre o volume da demanda a ser atendida. Por esses aspectos, não se poderia falar de uma forma de racionalidade capaz de reger todo trabalho. Portanto, o crescimento dos serviços não poderia ser analisado à luz da mesma racionalidade totalizadora. Existiriam, na interpretação de Offe (1989), diferenças inconciliáveis entre a produção de bens e de serviços. As construções do autor, no sentido de pensar as características que regem o trabalho nos serviços têm bastante pertinência, sobretudo para se refletir acerca dos aspectos qualitativos e humanos dos serviços, enquanto suas especificidades.

Todavia, ao explanar acerca do crescimento dos serviços, pautado pela crescente heterogeneidade no mundo do trabalho, o argumento de Offe (1989) corrobora a perda de centralidade do trabalho. Deve-se se refutar esta perspectiva, uma vez que, resguardadas as especificidades, tanto o trabalho em serviços quanto o trabalho na produção de bens, tem como aspecto homogeneizador a relação assalariada ou a mercantilização da força de trabalho. Neste âmbito, o crescimento no setor de serviços não representa o fim da centralidade do trabalho, mas denota a generalização da relação de venda da força de trabalho e a conseqüente incorporação do setor serviços à lógica de acumulação. Estes, segundo Augusto (1998), são aspectos desconsiderados na interpretação de Offe (1989).

É também no contexto de reestruturação produtiva que emergem as teses acerca do trabalho imaterial. Uma análise bastante pertinente a este respeito está em Amorim (2009), que analisa as teses do trabalho imaterial, a partir de alguns autores. Entre os quais: Gorz (1987; 2005), Negri, e Lazzarato (apud AMORIM, 2009). O trabalho imaterial é teoricamente tratado como

Um trabalho que é divulgado como social, mas que depende da qualificação individual; que se fundamenta na capacidade do reconhecimento da informação; que não pode ser restringido pelo capital, mas acaba por, novamente, circunscrever-se à lógica de valorização do capital. (AMORIM, 2009 p. 22).

As teses do trabalho imaterial, como força produtiva central, se vinculam a uma forma bastante específica das transformações no capitalismo. Segundo Amorim (2009) a teoria marxista, influenciada pela Segunda Internacional postulava a centralidade ao desenvolvimento econômico em geral, e das forças produtivas. Nesta perspectiva, comungava-se que o desenvolvimento das forças produtivas, pautado nos conflitos de classe, levaria a transição ao socialismo. A reestruturação da produção nos anos 1970 põe em xeque o industrialismo, eixo de análise do desenvolvimento das 
forças produtivas. Consequentemente, críticas são tecidas às interpretações baseadas no industrialismo. Este contexto forma um momento propício de rechaço à teoria marxista, sobretudo porque as teorias afiançadas do socialismo eram consideradas superadas.

Em primeiro lugar, houve um rechaço ao marxismo, sustentado nas teorias sobre a não centralidade do trabalho. Esse rechaço tinha como foco a negação ao trabalho industrial. No bojo desta discussão considerouse incontrolável o processo de substituição do trabalho humano pelo das máquinas. Não haveria outra alternativa para a classe trabalhadora além de aceitar e administrar este processo. Segundo Amorim (2009), o principal expoente desta corrente seria o autor André Gorz (1987). Sua perspectiva se fundamenta na ideia de que a teoria de classes sociais não dá conta das sociedades situadas no contexto da reestruturação produtiva.

Nesta direção, a heterogeneidade de profissões é considerada como um elemento que dificultaria a identificação dos indivíduos em uma determinada classe social. Paralelamente, no bojo deste discurso, na década de 1970, o trabalhador é relacionado diretamente ao seu posto de trabalho e suas qualificações técnicas indicam possibilidades para sua prática e consciência política; há uma forte relação entre os saberes empíricos e as potencialidades da classe trabalhadora como revolucionária; a liberação do tempo para a produção de mercadorias, com o aumento da produtividade (em função do desenvolvimento tecnológico), é caracterizado como elemento de contradição que colocaria o sistema em xeque. (AMORIM, 2009).

Haveria neste sentido um novo trabalhador, beneficiado pelas transformações tecnológicas do processo de produção. Esta condição lhe impôs adquirir conhecimento, estar mais qualificado. Estaria assim apto para barganhar melhores condições de trabalho.

O primado das forças produtivas, que na década de 1960/70 informava os tipos de organização política, sindical, e também qual seria o segmento de trabalhadores capacitados a revolucionar a sociedade capitalista, sempre erigido com base nas qualificações profissionais, passa na década seguinte a ser caracterizado em torno dos conteúdos cognitivos. (AMORIM, 2009, p. 148).

As teses desenvolvidas acerca do trabalho imaterial afiançam a este um caráter anticapitalista, mas situado dentro da organização da produção capitalista. A capacidade de adquirir novos conhecimentos e informações, como conteúdo característico do trabalho imaterial, facultaria aos trabalhadores competência para se organizarem politicamente. O conteúdo cognitivo, presente no trabalho imaterial, criaria uma negação à produção capitalista. Ao mesmo tempo, esta ideia traz a possibilidade de imposição da subjetividade do trabalhador frente ao capital. Segundo análise, a perspectiva dos chamados autores do trabalho imaterial é que o capital teria 
criado um problema sem solução em função de sua dependência em relação aos trabalhos cognitivos.

Neste âmbito, Amorim (2009) tece algumas críticas a estas elaborações. Primeiramente, ele refuta a ideia de os conteúdos cognitivos do trabalho imaterial estarem livres do controle do capital. Ao contrário, os processos de reestruturação produtiva têm assimilado formas de controle do trabalho que têm como base o conhecimento, o que pode ser verificado nos trabalhos, já mencionados, de Antunes (2001) e Valencia (2009). Ao mesmo tempo, isto permite inferir a centralidade do trabalho no processo de produção capitalista, uma vez que ao não conseguir excluir o trabalho vivo da produção, o capitalismo tem re-configurado novas formas de exploração do trabalho. Com efeito, questiona-se o caráter anti-capitalista atribuído ao trabalho imaterial, envolto na ideia de que o desenvolvimento das forças produtivas levaria a um devir, um processo automático de implosão da sociedade capitalista. A incorporação da informação, do conhecimento ou de qualquer qualificação profissional não pode determinar a formação de um sujeito revolucionário, que combata a estrutura das relações de produção capitalistas. A superação do modo de produção capitalista supõe considerar a luta de classes e, neste sentido, o desenvolvimento das forças produtivas no bojo de um processo histórico. (AMORIM, 2009).

Além disso, refuta-se a ideia de materialidade embutida nas teses sobre o trabalho imaterial. Amorim (2009) se refere à postulação de Marx (a qual foi apresentada no primeiro item deste artigo), segundo pouco importaria o conteúdo material do trabalho. A oposição entre trabalho imaterial e material seria um falso problema. Assim, a teoria de Marx remete ao conjunto de relações sociais, que tem um modo de produção referenciado na produção de mais-valia, que independe do caráter ou conteúdo do trabalho. Por fim, Amorim (2009), reforça que a diferenciação entre material e imaterial se relaciona ao trabalho concreto, na produção de valor de uso e não ao trabalho abstrato, enquanto produtor de valor de troca.

$\mathrm{Na}$ esteira desse debate, observa-se que as construções teóricas de Marx acerca dos serviços fornecem um norte à reflexão, uma vez que indicam que os serviços também são assimilados pela produção de maisvalia. Marx (1969) ressalta uma característica distintiva do trabalho em serviços, como trabalhos que não obtêm uma conformação objetiva, separada de seu produtor (como um objeto separado do produtor). Assim, "trabalhos que só se desfrutam como serviços não se transformam em produtos separáveis dos trabalhadores". Nestes, o "modo capitalista de produção só tem lugar de maneira limitada e pela própria natureza da coisa", conforme pode ser observado no primeiro item.

Com base nas proposições marxianas, pode-se afirmar que o trabalho em serviços envolve atributos imanentemente humanos (TRISTÃO, 2007). Este trabalho depende do saber, da qualificação, do prestador do serviço. Assim, este trabalho não pode ser subsumido realmente, diferen- 
temente da produção material, na qual se destacava a habilidade manual. Nesta, o capital conseguiu efetuar a subsunção real, com o domínio do processo produtivo, substituindo o trabalho humano por máquinas e tornando, consequentemente, trabalho humano apêndice da máquina, desqualificando o saber do trabalhador, enfim, seus atributos humanos. O desenvolvimento da maquinaria, aumentando a produtividade, permitiu ao capitalista explorar a mais-valia relativa. (MARX, 1969).

Não obstante,

Para tornar essa produção independente do homem o capital precisaria criar uma 'máquina' dotada de inteligência, sentimentos, criatividade, sensibilidade, intuição, enfim, teria que igualar essa máquina ao homem. Essa suposição fictícia, explorada amplamente pelo cinema, não se aplica ao mundo real. $O$ que nos faz concluir que por mais ampla que seja a utilização dos serviços para a valorização do capital, essa utilização encontra um limite bem claro, uma barreira. Barreira que consiste no próprio homem como ser genérico. Mesmo que alienado dessa sua natureza o homem jamais terá uma identidade absoluta com o capital, em outras palavras, o capital jamais poderá subsumir o trabalho imanentemente humano [...]. (TRISTÃO, 2007, p. 90).

Essa postulação não nega à atividade de serviços os dilemas acentuados pelos processos de reestruturação produtiva e suas formas características de gestão do trabalho, que são perversamente sentidos por toda classe trabalhadora. (VALENCIA, 2009). Nem coloca requisitos como a qualificação e conhecimento, utilizados nos serviços, como fatores característicos de uma categoria com conteúdo "revolucionário" (semelhante à perspectiva do trabalho imaterial). Também é inegável que estes aspectos têm atualmente sido incorporados na produção material. Estas transformações não negam a centralidade do trabalho, mas evidenciam perpetuação em diversas composições, que generalizam a relação de compra e venda da força de trabalho. Entretanto, estes atributos humanos, indispensáveis na realização dos serviços, são considerados como limites à captura total do trabalho vivo, e, portanto, são pertinentes para pensar os serviços assistenciais, nos quais se situa o trabalho do assistente social, que atende diretamente à população.

Ressalta-se, nesta direção, a análise conceitual da categoria serviço traçada por Meirelles (2006), no âmbito da economia política. Sua contribuição explicita a visão de autores clássicos (teóricos da metade do século XVIII até o século XIX) e a visão de autores contemporâneos acerca dos serviços. Ao analisar a literatura sobre serviços, a autora tem o mérito de explicitar as características que peculiarizam a atividade de serviços, como os atributos humanos neles fortemente presentes e indica que as classificações e tipologias delegam aos serviços uma posição residual em relação aos setores secundário e primário da economia. A autora também ressalta a presença da visão material e tangível da economia. Esta perspectiva conduz 
à classificação dos serviços como um produto (intangível) e não como processo, o que precisa, em sua opinião, ser repensado. A partir destas postulações conclui: "Serviço é trabalho em processo, e não o resultado da ação do trabalho, por esta razão elementar não se produz um serviço e sim se presta um serviço" (MEIRELLES, 2009, p.134.).

Este conceito faz eco à perspectiva de Marx ao afirmar que os serviços não obtêm uma conformação objetiva, separada de seu produtor, dependendo, portanto, de atributos estritamente humanos. Sob este prisma que nossa reflexão se dirige a apontar alguns limites e possibilidade do trabalho do assistente social, como um trabalhador prestador de serviços, visto que os atributos destacados são pertinentes para pensar este trabalho.

Neste contexto, se destacam os serviços assistenciais que, ao serem prestados à população, materializam as políticas sociais. Assim, a questão dos serviços tem especial relevância para o assistente social, uma vez que este profissional atua no âmbito do atendimento às demandas sociais dos usuários e também em relação ao acesso dos usuários a esses serviços. (IAMAMOTO, 2010). Neste sentido, a postulação de serviço como um trabalho em processo é pertinente para entender a dinâmica de funcionamento dos serviços assistenciais.

\section{O trabalho no campo dos serviços sociais: os assistentes sociais em foco}

Considerando que o Serviço Social, atua, historicamente, no âmbito dos serviços sociais, o trabalho do assistente social é demarcado por sua inserção em estruturas prestadoras de serviços sociais (TRINDADE, 2004). Com efeito, a dinâmica dos serviços sociais é afetada pelas inflexões no campo da intervenção estatal no campo da provisão do bem estar social inflexões estas com estreita relação com estágios de desenvolvimento econômico. Nesta direção não se pode escamotear os processos de reestruturação produtiva que têm colocado requisições ao trabalho no campo dos serviços sociais. Britos (2006) destaca as investidas de racionalização sobre o setor de serviços ainda que, segundo a autora, este campo não possa ser alvo dos mesmos processos de racionalização da produção industrial. Com base nas postulações de Offe (apud BRITOS, 2006) a autora chama a atenção para as estratégias de mecanização e racionalização introduzidas no setor de serviços. As primeiras concernem a medidas que diminuem tempo de trabalho (com emprego de equipamentos) e consequentemente postos de trabalho. Todavia, esbarra em questões nas quais a relação social dos serviços é necessária, ou seja, em que o fator humano é indispensável.

Un ejemplo adicional lo constituyen los medios electrónicos para el envío de información, que puede tornar inútil el trabajo de un mensajero), pero no se puede sujetar al funcionamiento de máquinas los 
procesos implicados en la relación de servicio. Las máquinas, en este caso, contribuyen secundariamente a mejorar la rapidez con que se pueden realizarse ciertas tareas, con frecuencia soportes o accesorias a dicha relación social. (BRITOS, 2006, p. 50).

No que tange às estratégias de racionalização, a autora menciona os incentivos para aumentar a produtividade dos trabalhadores, um maior controle sobre os horários de trabalho, um encurtamento de períodos de descanso, entre outros. "Estas estrategias se basan predominantemente en intentos de control del tiempo y el ritmo de trabajo, y producir una sobrecarga de trabajo reduciendo puestos y asignando funciones crecientes a los empleados.". (BRITOS, 2006, p. 51) Tal afirmação traz à tona aspectos criados ou acentuados pelos processos de reestruturação produtiva, que atingem o mundo do trabalho com diversas repercussões para classe trabalhadora. Estas estratégias têm sido revertidas para o setor de serviços sociais, mesmo considerando as dificuldades de estabelecer critérios de produtividade para a prestação destes serviços.

Neste sentido, o conceito de Meirelles (2006) de serviço como trabalho em processo e não como um resultado da ação, fornece um norte à reflexão. Na medida em que se considera o serviço não como produto, mas como algo que é prestado, se desvela um aspecto presente nestes serviços: o cunho interativo entre profissional e usuário; é um trabalho relacional (característica apontada, inclusive, pelo grupo de autores da visão contemporânea, conforme explanado na revisão bibliográfica). Assim, conforme lamamoto (2010), corroborando a perspectiva marxiana, o serviço não possui uma conformação objetiva e separada de seu prestador. Por isto, na prestação do serviço deve-se considerar o protagonismo do prestador deste serviço e do receptor deste mesmo serviço.

Tendo em vista a sua natureza relacional do serviço, no âmbito dos serviços assistenciais, pode-se pensar nestes como um trabalho que se constrói no espaço "interseçor" entre usuário e profissional, numa relação direta. Merhy $(1997$, p.90) ao abordar esta questão compara o trabalho de um marceneiro com o trabalho na saúde. A interseção entre marceneiro e consumidor é mediada pelo mercado e pelos seus produtos. Diferentemente: "Na saúde, ela se dá de modo imediato, tudo ao mesmo tempo." O fator humano presente nesta interseção revela as potencialidades dos serviços assistenciais.

Utilizando de outro exemplo fornecido por Merhy (1997, p.95), segue a citação abaixo:

[...] Ao descrevermos a produção de automóveis numa fábrica brasileira, podemos dizer que há uma tal ordem imposta ao processo produtivo na linha de produção que, se uma área como a forjaria não seguir os padrões definidos para ela na fabricação de seu produto, como por exemplo uma certa porta do carro, a área seguinte, como a da pintura, não irá nem aceitar o produto ofertado pela forjaria. 
Para o autor há um padrão na linha de produção que deve ser seguido, de modo que há uma "captura" total do trabalho vivo, que impede o autogoverno do trabalhador. No entanto, esta "captura" total do trabalho vivo não seria possível no espaço de um centro de saúde, por exemplo. "A 'captura' global do autogoverno nas práticas de saúde não é só muito difícil e restrita, mas impossível pela própria natureza tecnológica deste trabalho (MERHY. 1997, p.98)." Desta forma, conclui que o processo de trabalho em saúde "[...] está aberto ao que nele há de indeterminado, do que se define em ato, em produção permanente, nos espaços das 'interseções', produções e consumos" (MERHY, 1997, p.98). Com base na discussão deste autor, Costa (1998) afirma que a relação estabelecida na "interseção" entre usuário e o trabalhador de serviços, leva este tipo de trabalho a requerer uma relativa autonomia do profissional. Assim, considera-se a relativa autonomia uma característica dos serviços assistenciais, já que não se configuram em trabalho totalmente capturado.

Na literatura do Serviço Social, a questão da autonomia relativa tem espaço na discussão de alguns autores, dentre os quais lamamoto (2010). Nesse debate, a autora indica que a falta de maiores investimentos em estudos relativos à mercantilização da força de trabalho, situada na organização do trabalho coletivo em instituições empregadoras, dificulta a explicitação do significado da profissão, como trabalho abstrato e concreto, no âmbito da produção e da reprodução das relações sociais. Para ela, supõe-se elucidar o exercício profissional nos marcos do trabalho assalariado alienado. Nesta condição, o assistente social vivencia os dilemas da alienação e as determinações sociais que afetam toda classe trabalhadora.

O exercício profissional não foge a essas determinações sociais. $\mathrm{O}$ assistente social, ao ingressar no mercado de trabalho - condição para que possa exercer sua profissão como trabalhador assalariado vende a sua força de trabalho: uma mercadoria que tem valor de uso, porque responde a uma necessidade social e um valor de troca expresso no salário. O dinheiro que ele recebe expressa a equivalência do valor de sua força de trabalho com todas as outras mercadorias necessárias à sua sobrevivência material e espiritual [...]. (IAMAMOTO, 2010, p. 217).

A condição de assalariado cerceia sua autonomia. A própria realização do trabalho do assistente social depende de meios que são de propriedade das instituições empregadoras, como "recursos financeiros, materiais e humanos". O objeto de trabalho do assistente social sofre recortes pelas instituições empregadoras:

[...] A relação que o profissional estabelece com objeto de seu trabalho -, as múltiplas expressões da questão social, tal como se expressam na vida dos sujeitos com os quais trabalha-, dependem do prévio re-corte das políticas definidas pelos organismos empregadores, que estabe- 
lecem demandas e prioridades a serem atendidas. (IAMAMOTO, 2010, p. 421).

Nesse âmbito, o chamado poder institucional se coloca frente à autonomia do profissional, uma vez que o trabalhador não pode traçar livremente suas escolhas. A burocracia atravessa a realidade dos serviços. (KARSCH, 1987, p.26). Assim, os trabalhadores, no espaço dos serviços, muitas vezes, se apropriam da linguagem institucional, em detrimento dos próprios objetivos profissionais, que estão em tensão com aqueles postulados pelas instituições. E, desta forma, forja-se uma supremacia de técnicas e normas sobre o usuário. A burocracia presente nesta relação preserva o "segredo da competência", no termos de lamamoto (2010, p. 426), reproduzindo hierarquias presentes nas instituições. Para autora a burocracia também impregna o trabalho dos assistentes sociais e "assim, faz-se necessário estimular a criação de mecanismos passíveis de desburocratizar as relações com os sujeitos que reivindicam direitos e serviços, melhorando a qualidade do atendimento" (IAMAMOTO, 2010, p. 427).

Nesta direção, são as distintas formas de inserção profissional que determinam as condições em que se concretiza a autonomia profissional. O trabalho do assistente social se realiza em distintas relações sociais "[...] que condicionam a forma como se dá também a inserção deste trabalho no mundo do valor: como trabalho produtivo ou improdutivo de mais-valia, inscrito na esfera da produção de riqueza social ou da distribuição de mais-valia". (IAMAMOTO, 2010, p. 218). Por conseguinte, denota-se o seguinte pressuposto:

[...] não existe um processo de trabalho de Serviço Social, visto que o trabalho do assistente social é atividade de um sujeito vivo, enquanto realização de capacidades, faculdades e possibilidades do sujeito trabalhador. Existe, sim, um trabalho do assistente social e processos de trabalho nos quais se envolve na condição de trabalhador assalariado. (IAMAMOTO, 2010, p. 429).

É nos distintos espaços em que se insere que estão as tensões, marcadas pelo encontro das demandas das instituições empregadoras e dos usuários, que pode se forjar o protagonismo profissional do assistente social. Da mesma forma que existem os limites que cerceiam a autonomia profissional, explicitam-se algumas possibilidades, sobretudo porque é nas condições particulares do trabalho do assistente social que se repõe o dilema entre teleologia e causalidade. Para o enfrentamento deste dilema é que se faz mister que o profissional desenvolva competência teórico-metodológica para conhecer a realidade e articular o singular ao universal no conhecimento do modo de vida da população atendida (IAMAMOTO, 2010). Concomitantemente, o caráter do trabalho em serviços, enquanto um trabalho com atributos exclusivamente humanos, marcado pela relação ou 
espaço "interseçor" entre usuário e profissional, representa um campo profícuo de mediações, em que o profissional não tem seu trabalho totalmente capturado e padronizado. Muitas vezes, as ações profissionais vão à contramão das ações institucionais. Segundo Nogueira e Mioto (2006, p. 16),

O caráter institucional coloca um relativo limite ao recorte do objeto da ação profissional, na apreensão das demandas e definição de objetivos, condicionando, ainda, os resultados do trabalho. Por sua vez, as ações profissionais moldam comportamentos institucionais em uma relação dialética, assimétrica e determinada pelo jogo de interesses e forças condensadas em espaços sócio-ocupacionais.

Neste contexto, o assistente social pode re-elaborar as necessidades dos usuários, numa perspectiva ampliada. Isso supõe que a ação do profissional não pode se reduzir ao imediatismo do cotidiano. $\mathrm{O}$ assistente social convive com uma série de demandas trazidas pelos usuários e é preciso pensá-las e abordá-las na totalidade social. lamamoto (2010, p. 427) sinaliza que os assistentes sociais possuem uma série de denúncias referentes aos direitos humanos e sociais, as quais, com o devido sigilo, podem ser publicizadas em órgãos de representação e meios de comunicação, de forma a contribuir com a defesa destes direitos. A autora denota a necessidade de socialização de informações, na perspectiva do direito social, em que sujeitos individuais e coletivos tenham suas necessidades reconhecidas, a partir de sua realidade macrossocial. A socialização de informações permite que as demandas dos sujeitos sejam pensadas atreladas à coletividade. Mioto e Lima (2009) destacam neste sentido que no atendimento direto da população, o assistente social realiza ações de natureza educativa. Pode, através do diálogo e da informação, estabelecer um processo reflexivo com o usuário, buscando resolutividade às suas demandas, de modo a considerar sua autonomia.

É nesta direção que se pontua uma última indicação: o profissional deve ser impulsionado a buscar

[...] a integração de recursos sociais que forneça uma retaguarda aos encaminhamentos sociais e a articulação do trabalho com as forças organizadas da sociedade civil, abrindo canais para a articulação do indivíduo com grupos e/ou entidades de representação, capazes de afirmar e negociar interesses comuns na esfera pública. (IAMAMOTO, 2010, p. 427).

Estas indicações fornecem um norte para os assistentes sociais, mediante a realidade contraditória presentes nos espaços ocupacionais em que se inscrevem. Ao mesmo tempo, evidenciam algumas das possibilidades do trabalho do assistente social - possibilidades que podem ser favorecidas pelo caráter do trabalho em serviços - o qual é dependente de atributos exclusivamente humanos. 
Com base nessas indicações fornecidas pela literatura, é possível afirmar que no espaço dos serviços se desvelam uma série de elementos profícuos, no sentido de aprofundar o conhecimento do exercício profissional do assistente social. Além disso, fornece um norte para adensar o debate da dimensão técnico-operativa da profissão na direção do projeto ético e político do Serviço Social, comprometido com os dilemas da classe trabalhadora.

\section{Considerações Finais}

O Serviço Social, historicamente, atua no âmbito dos serviços sociais. Ao buscar subsídios para refletir esta inserção, as construções de Marx acerca de trabalho produtivo e improdutivo fornecem parâmetros para uma perspectiva crítica. Isto porque a concepção de trabalho produtivo e improdutivo, em Marx, não parte do conteúdo ou do caráter da atividade de trabalho concreto, "[...] mas do ponto de vista de sua forma social de organização, de sua compatibilidade com as relações de produção características da determinada ordem econômica da sociedade" (RUBIN, 1987, p. 280).

Na contemporaneidade, a dinâmica dos serviços sociais tem sido afetada pelas inflexões no campo da intervenção estatal no campo da provisão do bem estar social - inflexões estas com estreita relação com estágios de desenvolvimento econômico. Desta forma, os serviços não estão isentos dos dilemas acentuados pelos processos de reestruturação produtiva e suas formas características de gestão do trabalho, que são perversamente sentidos por toda classe trabalhadora (VALENCIA, 2009).

Neste trabalho buscou-se ressaltar também as peculiaridades do trabalho em serviços que implicam nos atributos humanos para sua realização e na possibilidade de não ser totalmente capturado. Nesta perspectiva, os atributos humanos, indispensáveis na realização dos serviços (pautados pelo cunho relacional, pela dependência da qualificação do trabalhador), são considerados aqui como limites à captura total do trabalho vivo. Portanto, têm pertinência para pensar os serviços assistenciais, nos quais se situa o trabalho do assistente social que atende diretamente a população. O profissional é, indiscutivelmente, afetado pelos dilemas do trabalho assalariado. Porém, a partir do cotidiano do exercício profissional, no qual se dá a prestação de serviços à população, é possível, conforme foi observado, pensar em estratégias de trabalho que ultrapassem a captura total do trabalho vivo. Ou seja, os atributos humanos intrínsecos ao trabalho em serviços e através dos quais a prestação dos serviços não adquire uma conformação objetiva, separada de seu prestador, revelam elementos fundamentais para a reflexão sobre as relações entre profissional e usuário no âmbito dos serviços sociais. 


\section{Referências}

ANTUNES, R. Os sentidos do trabalho: ensaio sobre a afirmação e a negação do trabalho. 4a . ed. São Paulo: Boitempo Editorial, 2001.

AMORIM, H. Trabalho imaterial: Marx e o debate contemporâneo. São Paulo: Annablune; FAPESP, 2009.

. Trabalho imaterial, classe social e qualificações profissionais. In: SOUZA, J.S.; ARAÚJO, R. Trabalho, educação e sociabilidade. Maringá: Práxis; Massoni, 2010, p. 154-172.

AUGUSTO, A. G. O fim da centralidade do trabalho? Pesquisa e Debate, São Paulo, v. 9, n. 2, p.87-104, 1998.

BRAVERMAN, H. Trabalho e capital monopolista: a degradação do trabalho no século XX. Rio de Janeiro: Guanabara, 3a. ed., 1974.

BRITOS, N. Ambito profissional y mundo del trabajo: politicas sociales y trabajo social en los años noventa. Buenos Aires: Espacio Editorial, 2006.

COSTA, M.D.H. Os serviços na contemporaneidade: notas sobre o trabalho em serviços. In: MOTA, A.E. (Org.). A nova fábrica de consensos: ensaios sobre a reestruturação empresarial, o trabalho e as demandas ao Serviço Social. São Paulo: Cortez, 1998, p. 97-113.

GORZ, A. Adeus ao proletariado: para além do socialismo. Rio de Janeiro: Forense, 1987. 2005. . O imaterial: conhecimento, valor e capital. São Paulo: Annablume,

IAMAMOTO, M.V. O serviço social em tempo de capital fetiche. São Paulo: Cortez, 2010.

KARSCH, U.M.S. O serviço social na era dos serviços. São Paulo: Editora Cortez, 1987.

LIMA, T.S.L.; MIOTO, R.C.T. A dimensão técnico-operativa do Serviço Social em foco: sistematização de um processo investigativo. Revista Textos \& Contextos. Porto Alegre v. 8 n.1 p. 22-48. jan./jun. 2009.

MARX, K. Capítulo VI inédito de O Capital: resultados do processo de produção imediata. São Paulo: Morais, 1969, p. 105 - 120.

. Teorias da mais-valia. Livro 4, v. 1. São Paulo: Bertrand Brasil, 1987, p.384-406. Disponível em: <http://www.marxists.org/portugues/marx/ 1863/mes/prodcapital.htm>. Acesso em: 27 jul. 2011.

- O Capital: crítica da economia política. Livro primeiro: o processo de produção do capital. v.1. 28 ed. Rio de Janeiro: Civilização Brasileira. 2011. 
MEIRELLES, D.S. O conceito de serviço. Revista de Economia Política, v. 26, p. 119-136, 2006. Disponível em: <http://www.scielo.br/pdf/rep/v26n1/ a07v26n1.pdf>. Acesso em: 13 set. 2008.

MERHY, E.E. Em busca do tempo perdido: a micropolítica do trabalho vivo em saúde. In: MERHY, E.E.; ONOCKO, R. (Orgs.). Práxis em salud: um desafío para lo público. São Paulo: Editora Hucitec, 1997, p. 71-112.

NOGUEIRA, V.M.R.; MIOTO, R,C.T. Sistematização, planejamento e avaliação das ações dos assistentes sociais no campo da saúde. In: MOTA, A.E. et al. Serviço social e saúde: trabalho e formação profissional. 2006. Disponível em: <http://www.fnepas.org.br/pdf/servico_social_saude/texto2-6.pdf >. Acesso em: 8 jan. 2008.

OFFE, C. (Org.). Trabalho uma categoria sociológica fundamental? In: TrabaIho e sociedade: problemas estruturais e perspectivas para o futuro da sociedade: Rio de Janeiro: Tempo Brasileiro, 1989, 1 v.

RUBIN, I. I. Teoria marxista do valor. São Paulo: Polis, 1987. 293p. (Coleção História e Teoria 13).

TRINDADE, R.L.P. Desvendando as determinações sócio-históricas do instrumental técnico-operativo do serviço social na articulação entre as demandas sociais e projetos profissionais. Temporalis: Associação Brasileira de Ensino e Pesquisa em Serviço Social, 2a ed. ano 2, n.4 (jul/dez., 2001) Brasília: ABEPSS, Gráfica Odisséia, 2004, p. 21-42.

TRISTÃO, E.L. A atividade de serviços na valorização do capital: um estudo sobre a natureza do trabalho docente no Ensino Superior Capitalista. 2007. 109 f. Monografia (Bacharelado em Economia) - UNESP, Araraquara, 2007.

VALENCIA, A.S. A reestruturação do mundo do trabalho: superexploração e novos paradigmas da organização do trabalho. Uberlândia: EDUFU, 2009.

Recebido em 29 de setembro de 2012.

Aprovado para publicação em 14 de dezembro de 2012. 